\section{At the frontiers in South America}

\section{Norman Myers}

Amazonia. Edited by Ghillean T. Prance and Thomas E. Lovejoy. Pergamon: 1985. Pp.442. £19.50, \$27.95.

A DOZEN or so scientific books dealing with Amazonia have appeared since 1980. This upsurge in professional interest is heartening, because it reflects a new awareness on the part of the scientific community both within Amazonian nations and elsewhere. After all, there is much to be aware about: with the richest biotic communities on Earth (one fifth of all species), Amazonia represents a kind of frontier for modern biology. Yet we know all too little about what makes it tick, let alone how to keep it ticking.

The region is also a frontier of different sort. The eight nations concerned want to develop it; that is, to exploit it, populate it, do something with it, rather than just leave it "idle" and unoccupied. Lacking science-based models of development, they have tended to employ approaches that owe more to notions of temperatezone development than to an appreciation of what Amazonia has to offer. Fortunately there are signs of a change in attitude, as governments and international agencies explore the creative challenges of a new frontier in the dual senses.

For all the outburst of writings, no book has reflected the intrinsic complexity of the region, whether seen from the standpoint of the scientist or the developer. Virtually all the material hitherto available is descriptive rather than analytical in style, and traditionally academic in spirit. How pleasing, then, to come across this book, a volume in Pergamon's Key Environments series, with its emphasis on relationships and interactions - and not only between biotas and their environs, and so on, but between scientific disciplines with all that should imply for coordination between government departments. The chapter on fish, for instance, reveals not only that Amazonia possesses 3,000 species (15 times as many as Europe), and that commercial fisheries could produce far more animal protein than do the region's cattle ranches; more to the point, we read about entire fish communities, including the 50 species that generate three-quarters of the commercial harvest, and that feed primarily off fruit fallen into the water. This bodes much for plans to turn the alluvial floodplains into rice fields by eliminating riverside forests.

A similar approach characterizes the chapters on soils, vegetation, agriculture, forestry, and useful plants and animals, among others. The most important chapter of all, however, is probably the one on climate. It shows how the Amazonian forest makes some of its own precipitation, and thus illustrates the ultimately integrative nature of the biospheric sciences; that is, life is not only modified by its environments but it adapts them as well, often to its own long-term benefit. This means that deforestation of part of Amazonia would reduce rainfall for the rest of the region, and thus alter the entire character of the remainder of the forest no matter how well protected it might be. It further implies that rainfall patterns would be affected in southern Brazil as well, this being the country's main cropgrowing zone.

\section{Insider's insects}

\section{Timothy J. Bradley}

Fundamentals of Insect Physiology. Edited by Murray S. Blum. Wiley: 1985 . Pp. 598. \$39.95, £41.40.

Despite the number and variety of biology students taking classes on insect physiology, we have hitherto lacked a comprehensive, detailed and up-to-date textbook on the subject. Fundamentals of Insect Physiology is a successful attempt to meet that need.

The book contains chapters on most of the traditional areas of physiology, including respiration, circulation, endocrinology, exocrine glands, and metabolism and behaviour, as well as discussion of topics related to neural and muscular function. Both its strengths and its weaknesses derive from the multi-author format. The information is in most part well presented and amazingly free of factual error, as is to be expected when experts are writing about their own specializations. Conversely, while the stylistic differences are not serious, the clarity of writing differs widely and there is little coordination between contributions on related topics.

Some of the chapters will unfortunately be of little use to beginning students of insect physiology. The lengthy account of electrical events in the nervous system is marred by confusing and poorly printed figures, and the examples are drawn largely from experiments using molluscan and mammalian material. More concise explanations of action and receptor potentials are available in basic physiology texts. The chapter on intermediary metabolism presents most of the metabolic pathways as confusing lists of reactions, rather than as pathways connected with arrows; for this topic, students would better be directed to Insect Physiology by Mordue et al. (Blackwell Scientific, 1980), an excellent but much less comprehensive textbook.
So here is a book to applaud. Within its 175,000 words, it encompasses the main components of the great Amazonian ecosystem. Several of the chapters are by Latin Americans, another welcome departure because most scientists interested in the region are still located in North America. My main regret is that there is not more text by the editors. Their twopage Introduction is splendid stuff: all the more pity, then, that they did not include commentaries on each chapter, or at least on the three main sections, with a concluding overview to pull the whole thing together.

Norman Myers, Upper Meadow, Old Road, Headington, Oxford OX3 8SZ, UK, is a consultant on development and environmental matters.

Most of the authors, however, present accurate and readable accounts of their fields. One of the many excellent contributions is the chapter on respiration by T.J. Nation. After a detailed description of morphological adaptations, both in body plan and at the organ and cellular levels, the author proceeds to a mathematical discussion of the physical laws underlying the diffusion of gases, ventilation and the metabolic rate of insects in various physiological states. This is followed by an analysis of specific respiratory adaptations (in pupae, aquatic insects and eggs), with examples of species possessing each type of adaptation. This last feature will be helpful for students faced with the bewildering morphological and taxonomic diversity of insects, for example among those possessing tracheal gills. All of the chapters contain references to review articles and sometimes to the primary literature.

The sequence of material could have been better; for example a discussion of the effects of hormones on behaviour precedes the chapter on endocrinology. Worse, however, is the choice of the opening chapter. My heart goes out to the students who, using this book, begin their acquaintance with insect physiology by reading a rather opaque discussion of the embryology of the insect heart.

The dust jacket indicates that the book is intended "both as a text for courses in insect physiology and as a basic reference for entomologists, zoologists, pest managers and physiologists". We already have an abundance of material in the second role, and it is as a basic text that Fundamentals of Insect Physiology has the most to offer. One hopes that later editions will continue to emphasize this aspect. Even as it stands, however, I consider it to be the best such textbook available.

Timothy J. Bradley is in the Department of Developmental and Cell Biology, University of California at Irvine. Irvine, California 92717, USA. 